\title{
Comparison of Volatile Compounds Profile and Antioxydant Activity of Allium sativum Essential Oils Extracted using Hydrodistillation, Ultrasound- Assisted and Sono-Hydrodistillation Processes
}

\author{
Zakia Boubechiche ${ }^{\star 1,2}$, Nour-Eddine Chihib ${ }^{3}$, Charafeddine Jama ${ }^{4}$, Amina Hellal ${ }^{5}$ \\ ${ }^{1}$ Ecole Nationale Supérieure Agronomique, 16200 Alger, ALGÉRIE \\ ${ }^{2}$ Ecole Nationale Supérieure des Sciences de la Mer et l'Aménagement du Littoral, 16000 Alger, ALGÉRIE \\ 3Université de Lille1, CNRS, INRA, UMR 8207-UMET-PIHM, 369 rue Jules Guesde, CS 20039, 59651 Villeneuve d'Ascq, FRANCE \\ ${ }^{4}$ Université de Lille1, CNRS, ENSCL, UMR 8207-UMET-PSI, Avenue Dimitri Mendeleïev, CS 9010859652 Villeneuve d'Ascq, FRANCE \\ ${ }^{5}$ Laboratoire des Sciences et Techniques de l'Environnement, Ecole Nationale Polytechnique, 16200. Alger, ALGÉRIE
}

\begin{abstract}
Objective: This work aims to evaluate the impact of the use of ultrasound during essential oils extraction from garlic bulbs. Material and methods: The essential oils were extracted by Conventional Hydrodistillation method (HD), Ultrasound-Assisted hydro-distillation (US-HD) and Sono-hydrodistillation (SHD) and compared using yield profile, chemical composition and antioxidant activity. Results: Higher performances were obtained when the direct application of ultrasound were used. Indeed, SHD allowed a higher yield after only $30 \mathrm{~min}$ of extraction time against $70 \mathrm{~min}$ and $90 \mathrm{~min}$ for the US-HD and the HD respectively. Among the total identified compounds by GC/MS, Sulphur compounds were found to be the most abundant with qualitative similarities for the three processes. Essential oils showed a potential DPPH radical scavenging activity with IC50 values of $0.96,1.17$ and 1.23 respectively for the three HD, US-HD and SHD processes. Conclusion: The use of ultrasound for the extraction of essential oil from garlic reduced extraction time without causing significant changes in volatile composition and antioxidant activity.
\end{abstract}

Keywords: Garlic essential oil, GC-MS, Antioxidant activity, Hydrodistillation, Ultrasound.

\section{INTRODUCTION}

Garlic (Allium sativum L.) is considered as one of the twenty most important vegetables, with various uses throughout the world, either as a raw vegetable for culinary purposes, or as an ingredient of traditional and modern medicine. Furthermore, it has also been proposed as one of the richest sources of total phenolic compounds, among the usually consumed vegetables, and has been highly ranked regarding its contribution of phenolic compounds to human diet. ${ }^{1}$ Garlic is a particularly rich source of organosulfur compounds that are partly responsible for the beneficial effects of garlic on health and allicin is a reactive sulfur species (RSS).,3,4
Garlic essential oil which concentrates the bioactive components, presents also properties such as antibacterial, antifungal and antioxidant. ${ }^{5,6}$ The quality and concentration of the targeted compounds can be substantially affected by the applied extraction method. Although conventional methods are most commonly used to extract essential oil from plants, they have some shortcomings, such as the difficultly to control the heat transfer throughout the process and the extensive extraction time. Moreover, many natural products are thermally unstable and can damage during thermal extraction. With growing a flavour and fragrance
DOI: 10.5530/ijper.51.3s.30 Correspondence:

Zakia Boubechiche, Ecole Nationale Supérieure des Sciences de la Mer et de l'Aménagement du Littoral, 16000 Alger, ALGÉRIA. Contact: +33 650573733 E-mail: boubechichez@ yahoo.fr 
industry and the increasing demand for more natural products, the need for novel extraction methods has become more intense. ${ }^{7}$ The extraction of essential oils using the ultrasonic assisted procedure has been recommended by several authors as one of the most efficient extraction system by allowing greater penetration of the solvent into the matrix of plant material under the cavitation effect thus facilitating the release of extractable compounds and reducing the extraction time. ${ }^{8}$ This work describes a comparative study, in term of quality and antioxidant activity of the essential oils of garlic bulbs extracted by conventional hydrodistillation and new innovative processes using ultrasound technology.

\section{MATERIALS AND METHODS}

Chemicals and plant material: A. sativum plants were harvested from plains in the east of Algeria in June 2014. Butylated hydroxyanisole (BHA) and 2,2-Diphenyl-1-picrylhydrazyl (DPPH) were purchased from Sigma Aldrich (St. louis, Mo, USA). All other chemicals were of analytical reagent grade.

Extraction procedures: The essential oils were extracted by the conventional method and new innovative processes, as shown in Figure 1. The collected essential oils were dried with anhydrous sodium sulphate and stored in dark-sealed-vial at $4^{\circ} \mathrm{C}$ until analysis. All extractions were performed at least three times.

Hydrodistillation (HD) procedure: About 200g of fresh bulbs were crushed with $100 \mathrm{ml}$ of deionized water for 2 min using a commercial blender. The obtained mixture was then diluted to final volume of 2L with deionized water and subjected to hydrodistillation in a Clevenger-type apparatus (recommended by pharmacopeia, Figure 1.a) until no more essential oil was obtained.

Ultrasound-assisted hydrodistillation (US-HD): Ultrasonic assisted extraction was performed using the Heilscher UP200Ht ultrasonic processor operating at 200W, $26 \mathrm{kHz}$ (Figure 1b).The garlic bulbs prepared under the same conditions described above were sonicated at $60 \%$ amplitude, continuously for 20 minutes. After then, the mixture was subjected to a conventional hydrodistillation.

Sono-hydrodistillation (SHD) : In this method, extraction of the essential oil from the garlic was carried out using the modified Clevenger apparatus described by Pingret et al. (Figure 1c). The ultrasonic probe was introduced into the second neck of the boiling flask containing the garlic bulbs, in order to release the ultrasonic waves directly into the matrix. The ultrasonic titanium probe system (UP200Ht operating at $26 \mathrm{kHz}$ and $200 \mathrm{~W}$ ) was maintained at amplitude of $60 \%$, discontinuously at a range of $3 \mathrm{~min}$.

Gas chromatography- mass spectrometry (GC/ MS) analysis: The extracted essential oil was analyzed using GCMS-QP5050A (Shimadzu, Japan) equipped with a FID detector and a capillary column SE30 (polydimethylsiloxane, $50 \mathrm{~m} \times 0.25 \mathrm{~mm}$, film thickness $0.25 \mu \mathrm{m})$. The injector and the detector temperatures were set at $250^{\circ} \mathrm{C}$ and $280^{\circ} \mathrm{C}$, respectively. $1 \mu \mathrm{l}$ of sample was injected manually with helium (the flow rate of $1.2 \mathrm{ml} / \mathrm{min}$ ) as carrier gas. The oven of temperature was initially kept at $50^{\circ} \mathrm{C}$ for $8 \mathrm{~min}$ and then gradually increased by $3 \mathrm{~min}$ to $250^{\circ} \mathrm{C}$ and held at $280^{\circ} \mathrm{C}$ for 15 $\min$.

The identification of the volatile compounds was performed by comparing the mass spectra with the spectra available in the Nist library. Confirmation of identification was made with reference to theretention indices calculated for all components using a homologous series of n-alkanes $\left(\mathrm{C}_{5}-\mathrm{C}_{28}\right)$ injected under the same conditions as the samples.

Free radical- scavenging activity: The DPPH radicalscavenging activity of the essential oil was measured using the method described by Brand-Williams et $a l^{10}$ The absorbance was measured at $517 \mathrm{~nm}$ using the UV-Visible spectrophotometer. BHA wasused as positive control. All tests were carried out in triplicate. Inhibi-
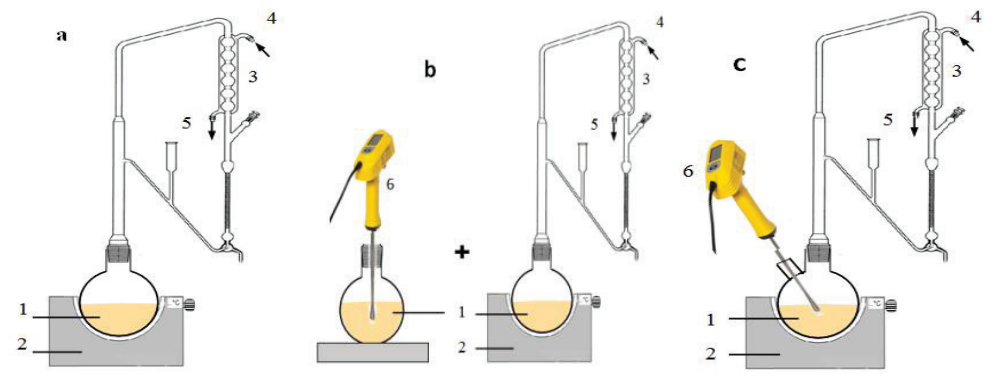

1. Mixture

2. Heating mantle

3. Condensor

4. Water out

5. Water in

6. Ultrasonic probe

Figure 1a: Conventional Hydrodistillation, b: Ultrasound-assisted Hydrodistillation, c: Sono-Hydrodistillation. 


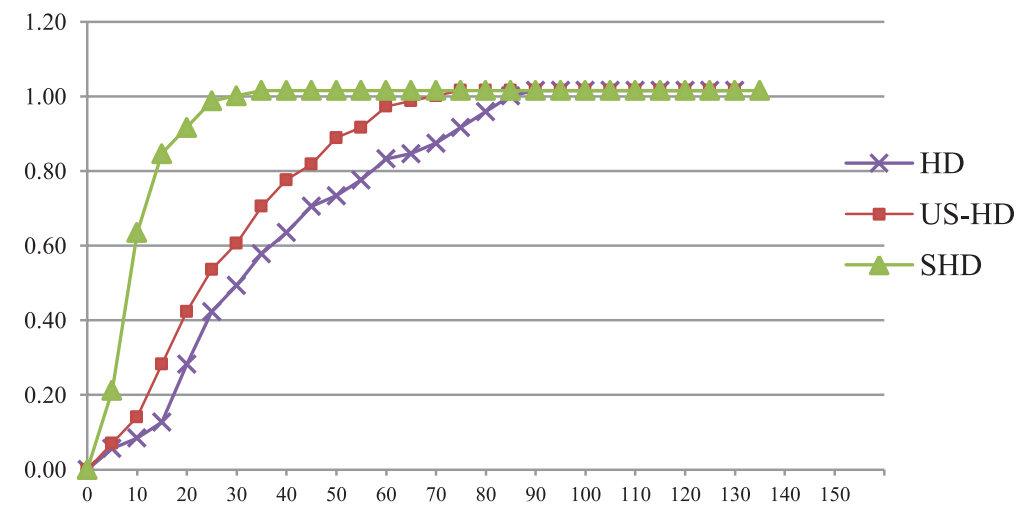

Figure 2: Yield profile of essential oil from fresh garlic bulbs obtained via different methods.

tions of DPPH radical in percent (\%) were calculated by the formula:

$$
\text { Inhibitions of DPPH activity }=\left[\left(\mathrm{A}_{0}-\mathrm{As}\right) / \mathrm{A}_{0}\right] \times 100
$$

Where $\mathrm{A}_{0}$ is the absorbance of the control sample (without antioxidant) and As is the absorbance of the sample. The concentration of antioxidant at which $50 \%$ of the reaction was inhibited $\left(\mathrm{IC}_{50}\right)$ was determined from the graph plotting inhibition percentage against concentrations of the sample.

\section{RESULTS AND DISCUSSION}

Extraction yield and chemical composition: The essential oils of the garlic bulbs extracted by the different methods were compared using yield profile, chemical composition and antioxidant activity. Figure 2, presenting the yield profiles, shows that a final yield of $1.02(\mathrm{~g} / 100 \mathrm{~g}$ Garlic bulbs) was obtained for the all three extraction processes (HD, US-HD, SHD) with significant differences in extraction time. SHD allowed a higher yield after only $30 \mathrm{~min}$ of extraction time against $70 \mathrm{~min}$ and $90 \mathrm{~min}$ for the US-HD and HD respectively. These results confirm the results of the literature, which indicate the high efficiency of ultrasound use in extraction of various plant materials. ${ }^{7}$ The essential oils obtained from each experiment, had common organoleptic properties. They had a mobile liquid appearance, a yellow color and a powerful and pungent odor. Table 1 shows high content of polysulfides for the three processes. Although, the comparison of isolated essential oils clearly showed a similarity on a qualitative basis, their quantities vary more or less depending on the extraction technique used. In the SHD and US-HD processes, the percentage of some abundant constituents such as diallyl disulfide, diallyl trisulfide is lower than in HD, which suggests that the use of coupled or assisted ultrasound may affect slightly the contents of some components.

Antioxidant activity : In the DPPH test, the antioxidants were able to reduce the stable, purple-coloured radical, DPPH, to the yellow- diphenylpricryhydrazine. The antioxidant has the capacity to act as donors of hydrogen atoms in the transformation of the DPPH radical into its reduced form DPPH-H. ${ }^{11}$ The Table 2, presents the free radical-scavenging of the essential oils. Lower $\mathrm{IC}_{50}$ values indicates higher antioxidant activity. All extracted essential oils showed the strongest radical scavenging effect with $\mathrm{IC}_{50}$ values of $0.96,1.17$ and 1.23 respectively for the three HD, US-HD and SHD processes. This remarkable antioxidant activity is partly due to the sulfur components, which represent the main constituents of these essential oils. ${ }^{3}$ However, a slight decrease in scanning activity is observed for both methods using ultrasound, which is explained by the slight degradation of certain components such as $d i$ et tri sulfides. Studies on the antioxidant activity of garlic revealed that this activity is attributed in particular to Diallyl polysulfides. ${ }^{4}$ It is important to note that although ultrasound has been shown to be effective in adapting conventional apparatuses as cited in some studies, ${ }^{12,9}$ some researchers have reported changes in organoleptic characteristics. ${ }^{13,14}$ Others described the degradation of antioxidants in food products when sonication is applied. ${ }^{14}$ From these observations it can be said that ultrasound has contributed effectively to the acceleration of the extraction process without leading to a remarkable degradation of both the quality and the antioxidant activity of the essential oil.

\section{CONCLUSION}

The present work indicates that extraction of the essential oil from garlic by sono-hydrodistillation provides 
Table1: Chemical composition of garlic essential oils obtained via the different methods

\begin{tabular}{|l|c|c|c|c|}
\hline Compounds $^{\mathbf{a}}$ & $\mathbf{R I}^{\mathbf{b}}$ & HD(\%) & US-HD(\%) & SHD(\%) \\
\hline Propylenesulfide & 642 & 0.03 & 0.02 & 0.03 \\
\hline MethylallylSulfide & 685 & 0.39 & 0.16 & 0.14 \\
\hline Dimethyldisulfide & 778 & 0.41 & 0.5 & 0.89 \\
\hline Diallyl sulfide & 784 & 3.5 & 2.1 & 2.73 \\
\hline Thiophene, 2,4 dimethyl & 874 & 0.02 & 0.03 & 0.04 \\
\hline 1.3Dithiane & 890 & 0.14 & 0.15 & 0.05 \\
\hline Methyl allyl ,disulfide & 918 & 1.19 & 1.22 & 1.28 \\
\hline Dimethyl trisulfide & 947 & 0.32 & 0.58 & 0.23 \\
\hline Diallyl disulfide & 1111 & 38.37 & 36.26 & 33.35 \\
\hline Methyl allyl trisulfide & 1116 & 8.2 & 8.67 & 11.67 \\
\hline 3-Vinyl-3,6- dihydro -1,2- dithiine & 1176 & 1.14 & 1.25 & 1.22 \\
\hline 3-Vinyl-3,4- dihydro -1,2- dithiine & 1201 & 2.02 & 2.06 & 2.02 \\
\hline Diallyltrisulfide & 1207 & 29.96 & 26.37 & 23.5 \\
\hline Diallyltetrasulphide & 1481 & 1.78 & 1.56 & 1.59 \\
\hline Yield (g oil/100gof Garlic bulbs) & & 1.02 & 1.02 & 1.02 \\
\hline Extraction time & & 90 & 70 & 30 \\
\hline
\end{tabular}

a Compounds are listed in order of their elution from the $\mathrm{SE}_{3} 0$ column.

${ }^{\mathrm{b}}$ retention indices relative to $n$-alkanes $\left(\mathrm{C}_{5}-\mathrm{C}_{28}\right)$ calculated on $\mathrm{SE} 30$ column.

Table 2: Antioxidant activity of garlic essential oils obtained via different methods

\begin{tabular}{|c|c|c|c|c|c|c|}
\hline \multirow{2}{*}{ Essential Oils } & \multicolumn{6}{|c|}{ DPPH Inhibition (\%) } \\
\hline & $1 \mathrm{mg} / \mathrm{mL}$ & $3 \mathrm{mg} / \mathrm{mL}$ & $6 \mathrm{mg} / \mathrm{mL}$ & $9 \mathrm{mg} / \mathrm{mL}$ & $12 \mathrm{mg} / \mathrm{mL}$ & $\mathrm{IC}_{50}$ * \\
\hline HD & $51.1 \pm 1,12$ & $54.4 \pm 0,39$ & $59.5 \pm 0,61$ & $64.4 \pm 0,67$ & $75 \pm 0.49$ & 0.96 \\
\hline US-HD & $51.23 \pm 0.66$ & $53.05 \pm 0.5$ & $59.77 \pm 1.21$ & $64.55 \pm 0.73$ & $75.21 \pm 0.65$ & 1.176 \\
\hline SHD & $50.74 \pm 0.83$ & $53.23 \pm 0.36$ & $59.36 \pm 1.03$ & $64.2 \pm 0.9$ & $74.2 \pm 0.8$ & 1.234 \\
\hline & $0.02 \mathrm{mg} / \mathrm{mL}$ & $0.04 \mathrm{mg} / \mathrm{ml}$ & $0.06 \mathrm{mg} / \mathrm{mL}$ & $0.08 \mathrm{mg} / \mathrm{mL}$ & $0.10 \mathrm{mg} / \mathrm{mL}$ & \\
\hline BHA & $45.33 \pm 0.88$ & $59.77 \pm 0.39$ & $82.28 \pm 0.79$ & $91.69 \pm 0.26$ & $93.89 \pm 0.68$ & 0.022 \\
\hline
\end{tabular}

$\mathrm{IC}_{50}{ }^{*}$ : concentration $(\mathrm{mg} / \mathrm{ml})$ for a $50 \%$ inhibition

yields comparable to those obtained by conventional hydrodistillation but with reduced extraction times and without notable differences in quality and antioxidant activity.

\section{ACKNOWLEDGEMENT}

Authors are thankful to Ministry of Higher Education and scientific Research of Algeria for financial support.

\section{CONFLICT OF INTEREST}

The authors have no conflict of interest.

\section{ABBREVIATIONS USED}

DPPH: 2,2-diphenyl-1-picrylhydrazyl; BHA: Butylated hydroxyanisole, IC50: concentration $(\mathrm{mg} / \mathrm{ml}$ ) for a $50 \%$ inhibition; HD: Hydrodistillation; US-HD: Ultrasoundassisted Hydrodistillation; SHD: Sono- Hydrodistillation.

\section{REFERENCES}

1. Martins N, Petropoulos S, Ferreira ICFR. Chemical composition and bioactive compounds of garlic (Allium sativum L.) as affected by pre- and post-harvest conditions: A review. Food Chem. 2016;211:41-50.

2. Borlinghaus J, Albrecht F, Gruhlke MCH, Nwachukwu ID, Slusarenko AJ. Allicin: Chemistry and biological properties. Molecules. 2014;19(8):12591-618.

3. Capasso A. Antioxidant action and therapeutic efficacy of Allium sativum L. Molecules. 2013;18(1):690-700.

4. Benkeblia N, Lanzotti V. Allium Thiosulfinates: Chemistry , Biological Properties and their Potential Utilization in Food Preservation. Food J. 2007;1(2):193-201.

5. Mnayer D, Fabiano-Tixier AS, Petitcolas E, Hamieh T, Nehme N, Ferrant C, et al. Chemical Composition, Antibacterial and Antioxidant Activities of Six Essentials Oils from the Alliaceae Family. Molecules. 2014; 
6. Pyun MS, Shin S. Antifungal effects of the volatile oils from Allium plants against Trichophyton species and synergism of the oils with ketoconazole. Phytomedicine. 2006;13(6):394-400.

7. Chemat F, Rombaut N, Sicaire AG, Meullemiestre A, Fabiano-Tixier AS, et al. Ultrasound assisted extraction of food and natural products. Mechanisms, techniques, combinations, protocols and applications. A review. Ultrason Sonochem. 2017;34:540-60.

8. Ramic M, Vidovic S, Zekovic Z, Vladic J, Cvejin A, Pavlic B. Modeling and optimization of ultrasound-assisted extraction of polyphenolic compounds from Aronia melanocarpa by-products from filter-tea factory. Ultrason Sonochem. 2015;23:360-8.

9. Pingret D, Fabiano-Tixier AS, Chemat F. An Improved Ultrasound Clevenger for Extraction of Essential Oils. Food Anal Methods. 2014;7(1):9-12.
10. Brand-Williams W, Cuvelier ME, Berset C. Use of free radical method to evaluate antioxidant activity. Leb und-Technologie. 1995;28(1):25-30.

11. Molyneux P. The Use of the Stable Free Radical Diphenylpicryl-hydrazyl (DPPH) for Estimating Antioxidant Activity. Songklanakarin J Sci Technol. 2004;26(2):211-9.

12. Djenni Z, Pingret D, Mason TJ, Chemat F. Sono-Soxhlet: In Situ UltrasoundAssisted Extraction of Food Products. Food Anal Methods. 2013;6(4):1229-33.

13. Pingret D, Fabiano-Tixier AS, Chemat F. Degradation during application of ultrasound in food processing: A review. Food Control [Internet]. 2013; 31(2):593-606. Available from: http://dx.doi.org/10.1016/j.foodcont.2012.11.039.

14. Adekunte AO, Tiwari BK, Cullen PJ, Scannell AGM, O'Donnell CP. Effect of sonication on colour, ascorbic acid and yeast inactivation in tomato juice. Food Chem [Internet]. 2010;122(3):500-7. Available from: http://dx.doi. org/10.1016/j.foodchem.2010.01.026.

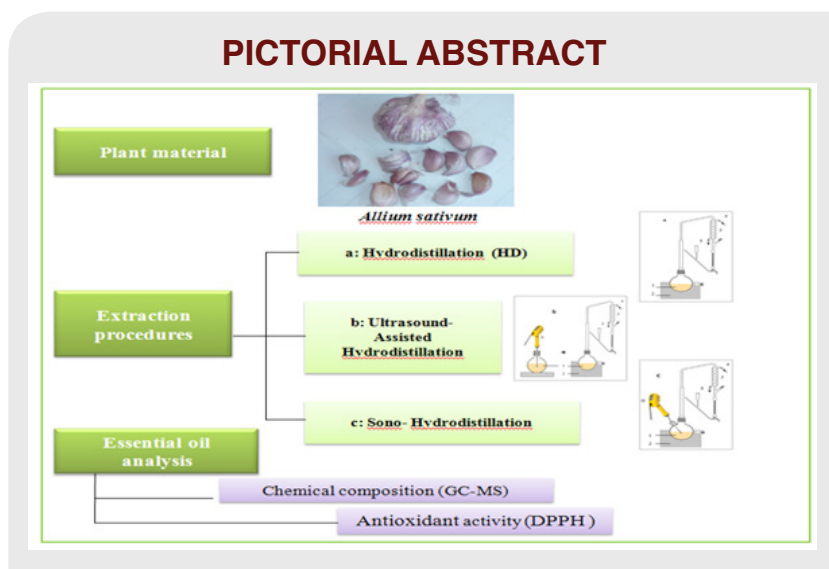

\section{SUMMARY}

- This study reports the impact of the use of ultrasound during essential oils extraction from garlic bulbs.

- The Sono Hydrodistillation method provides a yield comparable to those obtained by conventional hydrodistillation.

- Direct use of ultrasound significantly reduces the time extraction without notable differences in quality and antioxidant activity.

- The Sono Hydrodistillation extraction can be considered a novel technique.

\section{ABOUT AUTHORS}

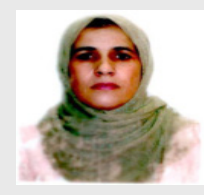

Zakia Boubechiche is a lecturer at the National School of Marine Science and Coastal Planning in Algiers. She is a specialist in food microbiology. She is working on bioactive compounds of aromatic and medicinal plants.

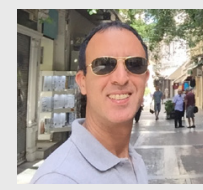

Prof. Nour Eddine CHIHIB presented his PhD Thesis in 1998 at the University of Science and technology of Lille on stress physiological response of food spoilage microorganisms. He started his research career since (1995) at the University of Science and technology of Lille. He is author of more than 60 research papers in international journals. In 2015, he joined the UMET UMR CNRS 8207 laboratory as Professor and he is developing research on antibacterial and antibiofilm strategies.

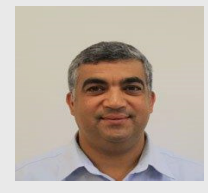

Prof. Charafeddine JAMA presented his PhD Thesis in (1995) at the University of Science and technology of Lille in Surface modification and thin films elaboration. He started his research career since (1990) at the University of Science and technology of Lille as chemical engineer and developed several industrial processes. He is author of more than 110 research papers in international journals. In 1999, he joined the UMET UMR CNRS 8207 laboratory as Professor and he is developing research on the extraction of essential oils for anticorrosion, antioxidant and antibacterial applications.

Amina Hellal is Professor-Director of Research in Biotechnology at National Polytechnic School of Algiers. She is Director of the laboratory of sciences and environmental techniques. She has vast experience in food and environmental biotechnology. She is author of research papers in international journals, books and conferences

Cite this article: Boubechiche Z, Chihib NE, Jama C, Hellal A. Comparison of Volatile Compounds Profile and Antioxydant Activity of Allium sativum Essential Oils Extracted using Hydrodistillation, Ultrasound-Assisted and Sono-Hydrodistillation Processes. Indian J of Pharmaceutical Education and Research. 2017;51(3)Suppl:281-85. 